Курысь Владимир Николаевич, Магин Владимир Алексеевич, Смышнов Константин Михайлович, Денисенко Вадим Сергеевич

\title{
ФИЗИЧЕСКАЯ ПОДГОТОВКА СТУДЕНТОВ ФАКУЛЬТЕТА ФИЗИЧЕСКОЙ КУЛЬТУРЫ В КОНТЕКСТЕ РЕАЛИЗАЦИИ ИДЕИ НЕПРЕРЫВНОСТИ ПРОФЕССИОНАЛЬНОГО ОБРАЗОВАНИЯ
}

В статье рассматривается профессионально направленная физическая подготовка будуцих специиалистов сферы физической культуры и спорта. Приводится ряд авторских взглядов и тезисов о месте и роли физической подготовки в профессиональном образовании, обосновывается целесообразность непрерьвности физической подготовки в период обучения в вузе и послевузовском образовании как условие развития и поддержания систем и функций организма человека в необходимом кондиционном состоянии в течение всего периода его жизнедеятельности.

Ключевые слова: образование, непрерывное образование, физическая подготовка.

Vladimir Kurys, Vladimir Magin, Konstantin Smyshnov, Vadim Denisenko PHYSICAL TRAINING OF STUDENTS OF FACULTY OF PHYSICAL CULTURE IN THE CONTEXT OF THE IMPLEMENTATION OF THE IDEA OF CONTINUITY OF PROFESSIONAL EDUCATION

In this article the professionally directed physical training of future specialists of the sphere of physical culture and sport is considered. A number of author's views and theses about the place and role of physical training in vocational education are given, the expediency of continuity of physical training during training at the University and postgraduate education as a condition for the development and maintenance of systems and functions of the human body in the required condition throughout the period of his life.

Key words: education, continuing education, physical training.

Bведение /Introduction. На современном этапе развития общества одним из наиболее перспективных направлений модернизации профессионального образования представляется идея обеспечения его непрерывности, особая важность которой заключается в постоянной активности педагогического сообщества, направленной на формирование у студентов вузов профессиональной компетентности в совокупности с нормами психофизического здоровья, общей культуры и нравственности, что обеспечивает возможность выпускника высшего учебного заведения к максимальной самореализации в будущем.

Пристальное внимание ряда отечественных и зарубежных исследователей проблеме зарождения и развития идеи непрерывного образования обуславливается целесообразностью познаний в этой области, которая может составить фундаментальные основы для современного научного обоснования и дальнейшего плодотворного расширения педагогического опыта в вопросах непрерывного образования.

Maтериалы и методы / Materials and methods. В качестве основных методов исследования были избраны ретроспективный анализ концепций и теорий непрерывного образования, образования в сфере физической культуры и спорта, контент-анализ ключевых дефиниций, используемых в научных работах, посвященных рассматриваемой проблеме, а также структурно-логический анализ федеральных образовательных стандартов и учебных планов вузов. 
Анализ состояния проблематики и проведенный ретроспективный анализ специальной научно-методической литературы свидетельствуют о том, что появление и развитие идеи непрерывного образования было основано на принципах гуманизации образования, которая просматривалась в гуманистических взглядах европейских исследователей Я. А. Коменского, Вольтера (Франсуа-Мари Аруэ), Ж-Ж. Руссо, И. В. Гёте и др. [4, 12].

Более широкое распространение идея непрерывного образования получила в Европе в эпоху Великой французской революции благодаря деятельности философа, математика и политического деятеля Ж. А. Кондорсе. В предложенном им проекте реформы народного образования основополагаюшими принципами образования провозглашались универсальность, всеохватность - доступность образования представителям всех слоев населения, преемственность и непрерывность [6].

В целом к настоящему времени сформировались три основные точки зрения на зарождение идеи непрерывного образования. Первая принадлежит сторонникам ее «древнего» происхождения [2], вторая отличается более поздним ее появлением в связи с интенсивными изменениями в различных сферах человеческой деятельности (производственной, научной, социальной, духовной и др.) [7], третья представляет собой симбиоз первых двух $[1,4]$.

В отечественной науке идея непрерывного образования также осталась не без внимания и рассматривалась в трудах прогрессивных педагогов Н. И. Пирогова, К. Д. Ушинского, Д. И. Писарева и др. Авторами отмечалось огромное значение непрерывного образования для развития человека и общества в целом [10].

В контексте рассматриваемой проблематики остановимся на некоторых аспектах в трактовке понятия «непрерывное образование». В современной педагогике это понятие рассматривается с разных позиций и имеет ряд толкований.

С одной стороны, «непрерывное образование» представляет собой систему взглядов на учебную деятельность человека как обязательную и естественную составляющую его жизнедеятельности в любом периоде онтогенеза [5]. Такая позиция ставит целью непрерывного образования пожизненное расширение потенциала человека, чем обусловлена необходимость «достройки» образовательной лестницы новыми ступенями для каждого периода взрослой жизни.

С другой стороны, под непрерывным образованием понимается формирование и постоянное совершенствование профессиональных компетенций человека, обоснованное его стремлением оставаться актуальным в своей профессии и социальной среде [9].

Отличия в существующих трактовках рассматриваемого понятия обусловлены, на наш взгляд, разнообразными аспектами социальной действительности и особенностями субъектов образовательного процесса, которые постоянно обучаются и совершенствуются, при этом процессы образования, воспитания и развития, непрерывные по характеру своего воздействия на человека, оказываются тем эффективнее, чем дольше продолжается их активное воздействие.

В период обучения студента в вузе воздействие отмеченных процессов существенно, однако после окончания учебного заведения результаты их воздействия начинают снижаться и даже нивелируются по причине нарушения основного принципа - принципа непрерывности развивающего воздействия.

Pезультаты и обсуждение / Results and discussion. Сама идея непрерывного образования послужила основой для создания в современной науке различных узкоспециализированных концепций, суть которых заключается в положительном переносе фундаментальных положений непрерывности процессов и явлений на определенную сферу социальной действительности. В работах А. В. Даринского, Г. П. Зинченко, И. И. Римаревой, И. В. Кулешова обосновывается целесообразность придания процессу образования характера непрерывности для повышения его общей эффективности $[2,4,5,11]$. 
Применительно к сфере физической культуры и спорта такой является концепция общего непрерывного образования человека в области физической культуры в онтогенезе $[3,8]$. Актуальность системы взглядов, изложенной в концепции, объясняется тем, что в современном образовании не прослеживается системных, научно обоснованных представлений о теории, методологии, содержании и организации общего и профессионального образования человека в области физической культуры в онтогенезе.

Анализ ФГОС по направлению подготовки 49.03.01 Физическая культура показал, что в целом набор компетенций (в соответствии с видами деятельности) направлен на формирование у студентов способностей воспитания у будущих учеников профессионально значимых качеств, мотивации к занятиям избранным видом спорта, моральных принципов честной спортивной конкуренции, навыков здорового образа жизни и др. Вместе с этим целенаправленное обеспечение повышения уровня физической подготовленности самих студентов в период их обучения в вузе представлено лишь одной компетенцией (например, ПК-14 - способностью осуществлять самоконтроль, оценивать процесс и результаты индивидуальной спортивной деятельности, сохранять и поддерживать спортивную форму), что явно недостаточно для формирования устойчивой осознанной мотивации на развитие и поддержание систем и функций организма в необходимом кондиционном состоянии в последующие периоды профессиональной деятельности учителя физической культуры или тренера.

Как показывает анализ учебных планов, физическая подготовка студентов осуществляется опосредованно в процессе реализации учебных программ спортивно-педагогических дисциплин (легкая атлетика, баскетбол, плавание, гимнастика и др.), направленных на формирование у студентов способностей осуществлять спортивную подготовку в избранном виде спорта с учетом особенностей занимающихся на основе положений дидактики, теории и методики физической культуры и требований стандартов спортивной подготовки, которые к последнему курсу, как правило, нивелируются дисциплинами теоретической направленности.

Рассматривая непрерывность как некую стратегическую идею развития профессионального образования в сфере физической культуры и спорта, интегральной целью которой является обеспечение максимальной самореализации человека в профессиональной деятельности, приходится признать, что до сих пор научно обоснованные представления о преемственности основных элементов современной системы непрерывного профессионального образования в сфере физической культуры и спорта и об особенностях процесса непрерывного профессионального образования в период последующей послевузовской трудовой деятельности сформированы не в полной мере.

Таким образом, идея непрерывности профессионального образования в настоящее время остается недостаточно востребованной и не занимает должного места в процессе подготовки специалистов сферы физической культуры и спорта. Отмеченное относится ко всему процессу в целом, а значит, и ко всем его составляющим, в том числе и физической подготовке. В этой связи физическая подготовка должна рассматриваться как составная часть образования в сфере физической культуры и спорта, которой присущи все закономерности, связанные с обеспечением непрерывного профессионального образования.

Суть универсальности и всеохватности физической подготовки заключается в положительном влиянии ее результатов не только на эффективность формирования у студентов специфических профессионально значимых компетенций, но и на утверждение постоянно действующей доминанты необходимости непрерывности профессионально направленной физической подготовки и функциональной подготовленности, востребуемых как в учебных, так и в будущих профессиональных целях.

Заключение / Conclusion. Вышеизложенное позволяет сформулировать ряд тезисов о месте и роли физической подготовки в непрерывном профессиональном образовании в сфере физической культуры и спорта: 
- физическая подготовка дискретного характера ведет к содержательно-временной ограниченности интеллектуальной и телесно-двигательной составляющих процесса профессиональной подготовки студентов, что противоречит принципу их единства, взаимосвязи и взаимообусловленности;

- физическая подготовка является одним из основных компонентов системы профессиональной подготовки будущих специалистов сферы физической культуры и спорта, она должна основываться на системном овладении знаниями и технологиями развития физических способностей и рассматриваться с позиций обеспечения непрерывности учебного процесса, обязывающего гарантировать постоянную (перманентную) преемственность эффекта занятий;

- специфический, практико-теоретический характер учебной деятельности студентов факультета физической культуры связан с необходимостью обеспечения непрерывности физической подготовки с целью постоянного повышения уровня физической подготовленности, пополнения и совершенствования биологических ресурсов организма, функциональной готовности к преодолению требуемых психофизических нагрузок и обеспечения эффективного овладения различными двигательными действиями;

- требуют более широкой представленности пути, формы и способы обеспечения непрерывности физической подготовки студентов на всех курсах обучения в университете, для чего следует акцентировать эту задачу как в перечне компетенций ФГОС по направлению подготовки 49.03.01 Физическая культура, так и в учебных планах вуза;

- значимость непрерывности физической подготовки на протяжении всего периода обуччения на факультете физической культуры определяется необходимостью формирования у студентов осознанной мотивации к регулярным занятиям физическими упражнениями для удовлетворения личностных специфических образовательных потребностей;

процессе физической подготовки студентов в период обучения в вузе позволит в дальнейшем двигаться в стратегическом направлении создания и постоянной актуализации модели профессионального здоровья, направленной на удовлетворение личностных потребностей и обеспечение в процессе трудовой деятельности предпосылок для здоровьесберегающего креативного долголетия.

\section{ЛИТЕРАТУРА И ИНТЕРНЕТ-РЕСУРСЫ}

1. Владиславлев А. П. Непрерывное образование как способ формирования всесторонне развитий личности // Философские науки. 1978. № 3.

2. Даринский А. В. Непрерывное образование // Советская педагогика. 1975. № 1.

3. Денисенко В. С. Физическая подготовка студента учебного заведения сферы физической культуры: монография / В. С. Денисенко, В. Н. Курысь, К. М. Смышнов, А. И. Яцынин. Ставрополь: Изд-во СКФУ, 2014. $163 \mathrm{c}$.

4. Зинченко Г. П. Предпосылки становления теории непрерывного образования // Сов. педагогика, 1991. № 1.

5. Кулешов И. В. Современная концепция непрерывного образования // Педагогическое обозрение. 2012. № 4.

6. Кулисевич Г. Проблемы непрерывного образования // ВВШ. 1988. № 1. С. 89.

7. Купцов О. В. Непрерывное образование руководителей и специалистов народного хозяйства // Советская педагогика. 1982. № 6.

8. Курысь В. Н. Концепция общего непрерывного образования в области физической культуры // V Международный конгресс «Человек, спорт, здоровье» 21-23 апреля 2011 г., Санкт-Петербург, Россия: материалы конгресса / под ред. В. А. Таймазова. СПб., Изд-во «Олимп-СПб», 2011. С. 125-126. 
9. Пережовская А. Н. Непрерывное образование: цели, задачи, содержание, функции, перспективы развития // Проблемы и перспективы развития образования: материалы VI Междунар. науч. конф. (г. Пермь, апрель 2015 г.). Пермь: Меркурий, 2015. С. 38-41.

10. Писарев Д. И. Избранные педагогические сочинения. М., 1984. 290 с.

11. Римарева И. И. Непрерывное образование определение, структура, специфика, проблема // Методист. 2004. № 4. С. 72-77.

12. Thomas E. J. Developing continuing education and training in European universities // Journal of European Industrial Training, 1995. Vol. 19. № 4. Pp. 11-15.

13. Long H. B. Adult and continuing education; responding to change. Amsterdam; N.Y.: Teachers College Press, 1983. 243 p.

\section{REFERENCES AND INTERNET RESOURCES}

1. Vladislavlev A.P. Nepreryvnoe obrazovanie kak sposob formirovaniya vsestoronne razvitij lichnosti (Continuing education as a way to form a fully developed personality) // Filosofskie nauki. 1978. № 3.

2. Darinskij A. V. Nepreryvnoe obrazovanie (Continuing education) // Sovetskaya pedagogika. 1975. №1.

3. Denisenko V. S. Fizicheskaya podgotovka studenta uchebnogo zavedeniya sfery fizicheskoj kul'tury: monografiya (Physical training of the student of educational institution of the sphere of physical culture) / V. S. Denisenko, V. N. Kurys', K. M. Smyshnov, A. I. YAcynin. Stavropol': Izd-vo SKFU, 2014. 163 p.

4. Zinchenko G. P. Predposylki stanovleniya teorii nepreryvnogo obrazovaniya (Prerequisites for the formation of the theory of continuing education) // Sov. pedagogika. 1991. № 1.

5. Kuleshov I. V. Sovremennaya koncepciya nepreryvnogo obrazovaniya (The modern concept of lifelong education) // Pedagogicheskoe obozrenie. 2012. № 4.

6. Kulisevich G. Problemy nepreryvnogo obrazovaniya (Problems of continuing education) // VVSH. 1988. № 1. P. 89.

7. Kupcov O. V. Nepreryvnoe obrazovanie rukovoditelej i specialistov narodnogo hozyajstva (Continuing education of managers and specialists of the national economy) // Sovetskaya pedagogika. 1982. № 6.

8. Kurys' V. N. Koncepciya obshchego nepreryvnogo obrazovaniya v oblasti fizicheskoj kul'tury (The concept of General continuing education in the field of physical culture) // V Mezhdunarodnyj kongress «CHelovek, sport, zdorov'e» 21-23 aprelya 2011 g., Sankt-Peterburg, Rossiya: materialy kongressa / pod red. V. A. Tajmazova. SPb.: Izd-vo «Olimp-SPb», 2011. P. 125-126.

9. Perezhovskaya A. N. Nepreryvnoe obrazovanie: celi, zadachi, soderzhanie, funkcii, perspektivy razvitiya (Continuing education: goals, objectives, content, functions, development prospects) // Problemy i perspektivy razvitiya obrazovaniya: materialy VI Mezhdunar, nauch. konf. (g. Perm', aprel' 2015 g.). Perm': Merkurij, 2015. P. 38-41.

10. Pisarev D. I. Izbrannye pedagogicheskie sochineniya (Selected pedagogical works). M., 1984. P. 290.

11. Rimareva I. I. Nepreryvnoe obrazovanic opredelenie, struktura, specifika, problema (Continuing education definition, structure, specificity, problem) // Metodist. 2004. № 4. P. 72-77.

12. Thomas E. J. Developing continuing education and training in European universities // Journal of European Industrial Training. 1995. Vol. 19. № 4. Pp. 11-15.

13. Long H. B. Adult and continuing education; responding to change. Amsterdam; N.Y.: Teachers College Press, 1983. 243 p.

\section{СВЕДЕНИЯ ОБ АВТОРАХ}

Курысь Владимир Николаевич, доктор биологических наук, профессор, профессор кафедры теории и методики физической культуры и спорта Института образования и социальных наук СКФУ. E-mail: vladimirkurys@mail.ru

Магин Владимир Алексеевич, доктор педагогических наук, профессор, проректор по воспитательной работе Северо-Кавказского федерального университета. E-mail: vmagin (a).ncfu.ru

Смышиов Константин Михайлович, кандидат педагогических наук, доцент, кафедра теории и методики физической культуры и спорта Института образования и социальных наук СКФУ, и. о декана факультета физической культуры Института образования и социальных наук СКФУ. E-mail: ksmyshnov@mail.ru

Денисенко Вадим Сергеевич, кандидат педагогических наук, доцент кафедры теории и методики физической культуры и спорта Института образования и социальных наук СКФУ. E-mail: Vadim.den7@mail.ru 


\section{INFORMATION ABOUT AUTHORS}

Kurys Vladimir, Doctor of Biological Sciences, Professor, Professor of the Department of theory and methodology of physical culture and sport of the Institute of education and social Sciences, NCFU. E-mail: vladimirkurys@mail.ru

Magin Vladimir, Doctor of Pedagogical Sciences, Professor, Vice-rector on educational work of the NorthCaucasus Federal University. E-mail: vmagin@.ncfu.ru

Smyshnov Konstantin, Candidate of Pedagogical Sciences, associate Professor, Department of theory and methodology of physical culture and sport of the Institute of education and social Sciences, NCFU, acting Dean of the faculty of physical education, Institute of education and social Sciences, NCFU. E-mail: ksmyshnov@mail.ru

Denisenko Vadim, Candidate of Pedagogical Sciences, associate Professor of the Department of theory and methodology of physical culture and sports Of the Institute of education and social Sciences of NCFU. E-mail: Vadim.den7@mail.ru

\section{Лукьянов Алексей Сергеевич, Воронина Татьяна Николаевна}

\section{ФОРМИРОВАНИЕ ПРОФЕССИОНАЛЬНОЙ МОТИВАЦИИ У СТУДЕНТОВ ВУЗА}

В статье представлен теоретический анализ и эмтирическое изучение особенностей формирования профессиональной мотивации у студентов вуза. Показана суциость профессиональной мотивации и описаны её компоненты: когнитивный, аффективный и конативный. Выделены условия её формирования, связанные с компонентами профессиональной мотивации, содержанием и организацией прочесса обучения студентов. Описаны результаты эмпирического исследования по формированио профессиональной мотивации студентов: представлена гипотеза, схема и результаты формирующего воздействия. Доказано, что создание специальных условий способствует формированию профессиональной мотивации студентов.

Ключевые слова: профессиональная мотивация, компоненты профессиональной мотиваци, студенты, формирование, педагогические условия.

Alexey Lukyanov, Tatyana Voronina

THE FORMATION OF PROFESSIONAL MOTIVATION UNIVERSITY STUDENT

The article presents a theoretical analysis and empirical study of the professional motivation formation among students. The essence of professional motivation is shown and its components-cognitive, affective and conative - are described. The conditions of its formation associated with the components of professional motivation, content and organization of the learning process of students. The results of empirical research on the formation of professional motivation of students are described: the hypothesis, scheme and results of the forming influence are presented. It is proved that the creation of special conditions contributes to the formation of professional motivation of students.

Key words: professional motivation, components of professional motivation, students, formation, pedagogical conditions.

Bвedeниe / Introduction. Мотивация студентов - одна из самых сложных проблем настоящего. Проблема мотива и формирования профессиональной мотивации студентов вуза является одним из приоритетных направлений исследований в современной социально-гуманитарной науке, несмотря на большое количество имеющихся на сегодняшний день работ в данной области. Так, в работах В. Г. Асеева, С. Д. Смирнова, Е. И. Степановой, А. А. Реана и др. изучается профессиональная и учебная мотивация студентов; мотивационный компонент как условие готовности 